\title{
Analisis Pertumbuhan dan Produksi Pisang Kepok Kuning Pada Dua Lokasi Tanah Di Desa Samberah Kecamatan Muara Badak Kabupaten Kutai Kartanegara
}

\section{Analysis of Growth and Production of Kepok Kuning Banana in Two Soil Locations in Samberah Village, Muara Badak District, Kutai Kartanegara Regency}

\author{
Rustam Baraq Noor \\ Tenaga Pendidik Program Studi Agroteknologi, Fakultas Pertanian, Universitas Widya Gama Mahakam \\ Jl. KH. Wahid Hasyim, Sempaja, Samarinda, Kalimantan Timur, Indonesia \\ rusbnoor@gmail.com
}

Diterima : 10 November Disetujui : 12 November 2020

\begin{abstract}
Soil fertility in banana cultivation varies and this is what makes Kepok banana production very dependent on it. Banana plants planted in new cleared land originating from the forest are very fertile and are very different from other former crops or bananas. Planting locations in hilly areas away from nutrient-carrying rivers are the last resort due to limited land. This study aims to determine the level of soil fertility on the growth and production of yellow Kepok banana in Samberah, Batu-Batu village, Muara Badak district, Kutai Kartanegara district. Implementation for four months from April to July 2020. The research design used a completely randomized design (CRD) repeated ten times. Fertility levels include former rice fields and former banana plant lands. The results showed that the land formerly planted with bananas was significantly different from the former land planted with rice in the circumference parameter. There was a tendency for the dominance of high parameter data, the number of tillers, and production on former banana plantations. Kepok Kuning banana plants do not choose the location of the land. So that the cultivation of yellow Kepok banana plants can be planted on former banana plantations sustainably.
\end{abstract}

Keywords: Kepok banana, growth, production, soil

\section{PENDAHULUAN}

Tanaman pisang kepok kuning memiliki prospek cerah seperti dilaporkan oleh Rizal M. dan Afrilia W. (2015) di kabupaten Kutai Timur dengan R/C rasio 2,82 yang berarti layak untuk dikembangkan.

Pisang kepok kuning yang dibudidayakan di kabupaten Kutai Kartanegara khususnya di kecamatan Muara Badak kabupaten Kutai Kartanegara kondisi pertumbuhan dan produksinya beragam. Hal tersebut terlihat dari jumlah sisir pada setiap tandannya penelitian terdahulu di kabupaten Kutai Timur dapat mencapai 14 sisir pertandan. Produksi pisang tersebut berbeda jauh dari hasil penelitian di kecamatan Muara Badak seperti dilaporkan oleh Hafis (2018) dengan jumlah sisir kurang dari 10 sisir.

Kesuburan tanah pada pertanaman pisang beragam dan inilah rupanya yang menyebabkan produksi pisang kepok sangat tergantung dengannya. Tanaman pisang yang ditanam di lahan bukaan baru yang berasal dari hutan sangatlah subur pertumbuhannya dan sangat berbeda jauh dibandingkan dengan lahan bekas tanaman lain atau pisang. Lokasi tanam di kawasan berbukit jauh dari aliran sungai pembawa hara adalah pilihan terakhir karena keterbatasan lahan.
Tujuan penelitian adalah untuk untuk mengetahui tingkat kesuburan tanah terhadap pertumbuhan dan produksi pisang kepok kuning yang berada di desa Sambera kecamatan Muara Badak desa Batu-batu kabupaten Kutai Kartanegara.

Pisang adalah tanaman yang berasal dari kawasan Asia Tenggara (termasuk Indonesia). Tanaman buah ini kemudian menyebar luas ke kawasan Afrika (Madagaskar), Amerika Selatan, Amerika Tengah dan selanjutnya merata keseluruh dunia seperti ditulis oleh Satuhu dan Supriyadi (1992). Tanaman pisang tidak menuntut persyaratan iklim dan tanah yang khusus sehingga dapat tumbuh dan berproduksi diberbagai benua.. Komoditi Buah pisang kaya akan sumber vitamin dan karbohidrat serta sangat digemari orang karena enak dimakan baik sebagai buah meja atau melalui pengolahan terlebih dahulu sehingga menjadikanya buah andalan nomor satu dunia.

Pisang kapok (Musa paradisiaca formatypica) merupakan salah satu buah pisang yang enak dimakan setelah setelah diolah terlebih dahulu. Pisang kepok memiliki buah yang sedikit pipih dan kulit yang tebal, jika sudah matang 
warna kulit buahnya akan menjadi kuning. Pisang kepok memiliki banyak jenis, namun yang lebih dikenal adalah pisang kepok putih dan pisang kepok kuning. Warna buahnya sesuai dengan nama jenis pisangnya, yaitu putih dan kuning. Pisang kepok kuning (Musa paradisiaca var. bluggoe) memiliki rasa yang lebih enak, sehingga lebih disukai masyarakat (Prabawati dkk, 2008) Budidaya pisang sangat tergantung dengan keberadaan lahan. Kesuburan lahan merupakan kunci sukses keberhasilan pertanaman. Pada tanah aluvial yang umumnya terdapat ditepi-tepi sungai Mahakam atau sungai lainnya di Kalimantan Timur, kondisi pertumbuhan tanaman pisang ummnya tumbuh subur.

Jenis tanah yang disukai tanaman pisang adalah tanah liat yang mengandung kapur atau alluvial dengan $\mathrm{pH}$ antara 4,5-7,5. tanah berat kaya humus, mengandung kapur Tanaman ini rakus makanan sehingga sebaiknya tanaman pisang ditanam di tanah berhumus disertai pemupukan yang berimbang, dengan air harus selalu tersedia tetapi tidak boleh menggenang (Suyanti dan Ahmad 2009). Tanah yang telah mengalami erosi tidak akan menghasilkan panen pisang yang baik. Tanah harus mudah meresapkan air. Pisang tidak hidup pada tanah pada tanah yang mengandung garam $0,07 \%$ (Redaksi Trubus, 2008).

Pemilihan lahan untuk budidaya pisang khususnya pisang kepok sangatlah penting karena tanaman pisang tergolong tumbuhan yang rakus hara sehingga dianjurkan satu lahan hanya ditanami maksimal tiga siklus produksi (Kemenegristek 2000).

Karena keterbatasan lahan subur dengan jenis tanah alluvial ditepi sungai maka pemilihan lokasi tanam di tanah yang jauh dari tepi sungai dengan tingkat kesuburan yang beragam, sehingga pertumbuhan pisang tidak sebagus di aliran sungai.

Pertumbuhan tanaman pisang kepok sangat menghendaki tanah banyak mengandung humus, subur dengan air yang cukup tidak tergenang. Tentang kesuburan tanah pada pertanaman pisang sangatlah berpengaruh seperti dilaporkan Noor dan Arsensi (2018) bahwa tanaman pisang yang tidak dipupuk pertumbuhan morfologinya berbeda dengan yang dipupuk.
Data produksi pisang kepok, berat pisang kepok setiap tandan mencapai $14-22 \mathrm{~kg}$ dengan jumlah sisir 10 - 16 sisir, setiap sisir $12-$ 20 buah. Ukuran panjang buah $10-12 \mathrm{~cm}$ dan berat per buah 80 - $120 \mathrm{~g}$ (Satuhu dan Supriyadi, 1992 ; Widyastuti dan Paimin, 1993. Jumlah sisir pisang kopok seperti yang disebutkan jarang ditemui di pasar-pasar.. Kondisi tersebut sangat kontras dengan hasil penelitian di desa Batu-batu kecamatan Muara Badak dengan jumlah $5-7$ sisir pertandan (Noor, R.B.2017).

Total produksi pisang secara nasional sebesar 1.788.428 ton (BPS, 2017) dengan sentra produksi pulau Jawa.

Peningkatan produksi dengan penerapan cara budidaya sehat pada petani pisang Sambera desa Batu-batu kecamatan Muara Badak, yang meliputi penggunaan tanaman sehat, pemupukan, pengaturan jumlah anakan, pemangkasan daun tua dan kering ternyata mampu meningkatkan produksi mencapai sepuluh sisir pertandan pisang kepok kuning seperti dilaporkan oleh Noor dan Arensi.I. 2018.

Konsumsi buah dan sayur hasil Survei Konsumsi Makanan Individu (SKMI) tahun 2014 oleh Hermina dan Prihatini bahwa rata-rata konsumsi sayur penduduk 70,0 gram/orang/hari dan konsumsi buah 38,8 gram/gram/orang/hari. Total konsumsi sayur dan buah penduduk 108,8 gram/orang/hari jauh dibawah standar WHO yaitu sayur 250 g/orang/hari buah $150 \mathrm{~g}$ /orang/hari = $400 \mathrm{~g} / \mathrm{orang} /$ hari.

Kesenjangan konsumsi dan produksi buah yang salah satunya komoditi pisang menjadi suatu prioritas kearah perbaikan budidaya tanaman pisang secara lestari terutama pada kesuburan tanah.

\section{BAHAN DAN METODE}

Penelitian dilaksanakan selama empat bulan yakni dari April 2020 sampai dengan Juli 2020 dengan mengambil tempat Sambera desa Batu-batu kecamatan Muara Badak kabupaten Kutai Kartanegara. Rancangan penelitian yang menggunakan Rancangan Acak Lengkap dengan lokasi lahan sebagai faktor tunggal, terdiri dari dengan dua lokasi lahan yaitu lahan bekas tanaman padi (BPa, Lahan bekas tanaman pisang (BPi). Setiap lokasi lahan diulang sebanyak sepuluh kali. Setiap rumpun pisang yang dijadikan objek penelitian berisi 
4-16 pohon dengan satu atau dua pohon yang berbuah.

Parameter pengamatan untuk data tingkat kesubutan tanah pada dua lokasi meliputi :

1. Mengambil data tinggi tanaman, lingkar batang dan jumlah anakan dalam satu rumpun

2. menghitung jumlah sisir setiap tandang pohon pisang kepok kuning yang sudah dibuang jantungnya dan menjelang tua

3. Mengambil sampel tanah pada Lahan bekas ditanami padi (BPi) dan Lahan bekas ditanami pisang (BPa) Sambera desa Batu-batu kecamatan Muara Badak untuk dianalisa pada laboratrium BPPT Kaltim di Samarinda.

\section{HASIL DAN PEMBAHASAN}

Penelitian pertumbuhan dan produksi pisang yang telah laksanakan di Samberah desa Batu-batu kecamatan Muara Badak kabupaten Kutai Kartanegara menghasilkan data yang meliputi tinggi, lingkar batang, jumlah anakan setiap rumpun dan produksi tanaman pisang.

Pengambilan data pada lahan bekas tanaman padi dengan luas lahan sampel $1000 \mathrm{~m} 2$ dengan rincian panjang $50 \mathrm{~m}$ dan lebar $20 \mathrm{~m}$ jumlah rumpun pisang 71 rumpun dengan tingkat keasaman tanah (pH) 5,8 ditampilkan pada tabel berikut:

Tabe1 1 Penelitian Analisis Pertumbuhan dan Produksi Pisang Kepok Kuning Pada lahan bekas tanaman padi di Samberah desa Batu-batu Kecamatan Muara Badak Kabupaten Kutai Kartanegara.

\begin{tabular}{lcccc}
\hline No Sampel & Tinggi $(\mathrm{cm})$ & Lingkar Batang $(\mathrm{cm})$ & Jumlah Anakan & Ber buah \\
\hline BPA 1 & 497 & 59 & 4 & 0 sisir \\
\hline BPA 2 & 503 & 65 & 7 & 0 sisir \\
\hline BPA3 & 445 & 51 & 7 & 0 sisir \\
\hline BPA4 & 523 & 62 & 12 & 0 sisir \\
\hline BPA 5 & 546 & 63 & 5 & 5 sisir \\
\hline BPA 6 & 550 & 62 & 9 & 0 sisir \\
\hline BPA 7 & 520 & 65 & 8 & 0 sisir \\
\hline BPA 8 & 585 & 70 & 5 & 0 sisir \\
\hline BPA 9 & 535 & 64 & 8 & 0 sisir \\
\hline BPA 10 & 427 & 44 & & 0 sisir \\
\hline
\end{tabular}

Tabel 2 Penelitian Analisis Pertumbuhan dan Produksi Pisang Kepok Kuning Pada lahan bekas tanaman padi Di Desa Sambera Kecamatan Muara Badak Kabupaten Kutai Kartanegara

\begin{tabular}{ccccc}
\hline No Sampel & Tinggi $(\mathrm{cm})$ & $\begin{array}{c}\text { Lingkar Batang } \\
(\mathrm{cm})\end{array}$ & Jumlah Anakan & Berbuah \\
\hline BPI 1 & 542 & 71 & 16 & 5 sisir \\
\hline BPI 2 & 560 & 84 & 12 & 5 sisir \\
\hline BPI 3 & 536 & 57 & 10 & 0 sisir \\
\hline BPI 4 & 530 & 70 & 7 & 4 sisir \\
\hline BPI 5 & 532 & 61 & 10 & 0 sisir \\
\hline BPI 6 & 515 & 57 & 5 & 0 sisir \\
\hline BPI 7 & 575 & 69 & 9 & 0 sisir \\
\hline BPI 8 & 590 & 76 & 9 & 0 sisir \\
\hline BPI 9 & 525 & 61 & 9 & 0 sisir \\
\hline BPI 10 & 493 & 64 & 3 sisir \\
\hline
\end{tabular}


Data produksi pada lahan ini (bekas tanaman padi) terlihat hanya 1 rumpun pisang pada yaitu pada sampel BPA5 dengan jumlah sisir 5 buah sedangkan 9 sampel lainnya tidak berbuah Selanjutnya data pada lahan tanaman pisang bekas tanaman pisang seluas $1000 \mathrm{~m}^{2}$ dengan jumlah 71 rumpun pada tingkat keasaman tanah (pH) 6,1 diperlihatkan pada tabel 2

\section{Tinggi tanaman}

Tinggi tanaman pisang kepok kuning yang diteliti pada lokasi Samberah desa Batu-batu kecamatan Muara Badak kutai Kartanegara disajikan pada tabel berikut:

Tabel 3 Tinggi tanaman pisang kepok kuning pada lahan bekas tanaman padi dan lahan bekas tanaman pisang Samberah desa Batu-batu kecamatan Muara Badak Kutai Kartanegara (cm)

\begin{tabular}{|c|c|c|c|c|c|c|c|c|c|c|c|c|}
\hline Perlakuan & 1 & 2 & 3 & 4 & 5 & 6 & 7 & 8 & 9 & 10 & Total & $\begin{array}{l}\text { Rata } \\
\text { Rata }\end{array}$ \\
\hline L. padi & 497 & 503 & 445 & 523 & 546 & 550 & 520 & 585 & 535 & 427 & 5131 & 513 \\
\hline L. pisang & 541 & 560 & 536 & 530 & 532 & 515 & 575 & 590 & 525 & 493 & 5397 & 540 \\
\hline Total & 1038 & 1063 & 981 & 1053 & 1078 & 1065 & 1095 & 1175 & 1060 & 920 & 10528 & \\
\hline
\end{tabular}

Data tinggi tanaman pisang kepok pada kedua lokasi penelitian tidak memperlihatkan perbedaan nyata. Pada lahan bekas tanaman pisang rata-rata tinggi tanaman pisang kepok kuning sedikit lebih unggul yaitu $540 \mathrm{~cm}$ dibanding $513 \mathrm{~cm}$ untuk lahan bekas tanaman padi. Perbedaan ketinggan rata-rata tanaman pisang memperlihatkan bahwa tanah lahan bekas tananan pisang mampu memberikan hara yang cukup bagi tumbuh kembang tanaman di atasnya.

\section{Lingkar batang}

Lingkar batang tanaman pisang kepok kuning yang diteliti pada lokasi Samberah desa Batu-batu kecamatan Muara Badak kutai Kartanegara disajikan pada tabel berikut:

Tabel 4 Lingkar batang tanaman pisang kepok kuning pada lahan bekas tanaman padi dan lahan bekas tanaman pisang Samberah desa Batu-batu kecamatan Muara Badak Kutai Kartanegara (cm)

\begin{tabular}{lcccccccccccc}
\hline & \multicolumn{10}{c}{ Lingkar Batang } \\
\hline Perlakuan & 1 & 2 & 3 & 4 & 5 & 6 & 7 & 8 & 9 & 10 & Total & Rata Rata \\
\hline L padi & 59 & 65 & 51 & 62 & 63 & 62 & 65 & 70 & 64 & 44 & 605 & 60,50 \\
\hline L. pisang & 71 & 84 & 57 & 70 & 61 & 57 & 69 & 76 & 61 & 64 & 670 & 67,00 \\
\hline Total & 130 & 149 & 108 & 132 & 124 & 119 & 134 & 146 & 125 & 108 & 1275 \\
\hline
\end{tabular}


Tabel 5 Analisi Beda Nyata Lingkar batang tanaman pisang kepok kuning pada lahan bekas tanaman padi dan lahan bekas tanaman pisang Samberah desa Batu-batu kecamatan Muara Badak Kutai Kartanegara (cm)

\begin{tabular}{|l|l|l|l|l|l|l|l|l|l|l|l|l|}
\hline Perlakuan & 1 & 2 & 3 & 4 & 5 & 6 & 7 & 8 & 9 & 10 & Rata rata & \\
\hline L padi & 59 & 65 & 51 & 62 & 63 & 62 & 65 & 70 & 64 & 44 & 60,50 & a \\
\hline L. pisang & 71 & 84 & 57 & 70 & 61 & 57 & 69 & 76 & 61 & 64 & 67,00 & b \\
\hline
\end{tabular}

BNT 5\% Lahan bekas padi dengan lahan bekas pisang $7,47 \%$ Hasil analisis BNT memperlihatkan data pada lingkar batang berbeda nyata pada lahan bekas tanaman padi dengan lahan bekas tanaman pisang.

Perbedaan nyata pada lahan bekas tanaman padi dengan bekas tanaman pisang pada data pengukuran lingkar batang menunjukan bahwa kedua lahan tersebut memiliki tingkat kesuburan yang berbeda yang didukung oleh tingkat keasaman $\mathrm{pH} 5,8$ pada lahan bekas tanaman padi di bandingkan $\mathrm{pH} 6,1$ untuk lahan bekas tanaman pisang. Selanjutnya untuk melihat tingkat hara nurtisi kesuburan tanah pada lahan bekas tanaman padi dengan lahan bekas tanaman pisang.

Tampak hara pada lahan bekas tanaman pisang lebih rendah dibanding bekas tanaman padi dengan tingkat keasaman $(\mathrm{pH})$ 6,02 untuk lahan bekas tanaman pisang dan $\mathrm{pH} 5,95$ untukTanaman padi. Buckman dan Brady (1982) (12) menyatakan bahwa unsur $\mathrm{N}, \mathrm{P}, \mathrm{K}, \mathrm{S}, \mathrm{Ca}$ dan $\mathrm{Mg}$ menjadi tersedia pada kisaran pH $6-7,5$. Artinya lahan bekas tanaman padi lebih tinggi kandungan hara NPK dibanding hara pada lahan bekas tanaman pisang namun karena unsur hara menjadi tidak tersedia untuk diserap akar tanaman pisang. Kondisi tersebut diperkuat dengan hasil analisis tanah oleh BPPT Kaltim 2020 yang menyatakan kandungan tekstur pada lahan bekas tanaman pisang dengan kandungan pasir sebesar $47,44 \%$ dibanding 21,09 \% untuk tanah bekas ditanami padi, begitu pula untuk debu dan liat lebih besar pada tanah dilahan padi. Kandungan hara tanah pada lahan bekas tanaman pisang lebih mudah tercuci karena memiliki kandungan pasir lebih banyak dan sebaliknya hara terikat pada keloid liat ditanah pada lahan bekas tanaman pisang (Hardjowigene, 2007).

Tabel 6 Hasil Analisis Tanah Samberak Desa Batu-batu Muara Badak Kutai Kukar

\begin{tabular}{|c|c|c|c|c|c|c|c|c|c|c|}
\hline \multirow{4}{*}{ No } & \multirow{4}{*}{$\begin{array}{c}\text { KODE } \\
\text { SAMPEL }\end{array}$} & \multirow{2}{*}{$\begin{array}{c}\text { pH } \\
\text { H2 O }\end{array}$} & \multirow{2}{*}{$\begin{array}{l}\text { Kadar } \\
\text { Air }\end{array}$} & \multicolumn{3}{|c|}{ Tekstur } & \multirow{2}{*}{$\frac{\mathrm{N}}{\text { Total }}$} & K2 O* & \multirow{2}{*}{$\begin{array}{c}\text { P2 } \\
\text { O5* }^{*} \\
\text { ial }\end{array}$} & \multirow{2}{*}{$\begin{array}{c}\text { P2 } 05 \\
\text { Tersedia }\end{array}$} \\
\hline & & & & pasir & debu & liat & & Potensial & & \\
\hline & & IKM.T02 & ЈVМ ТО? & & IKM.T07 & & IKM.T12 & \multicolumn{2}{|c|}{ IKM.TO8 } & IKM.T09 \\
\hline & & $\%$ & S & & $\%$ & & $\%$ & \multicolumn{2}{|c|}{$\mathrm{mg} \mathrm{P} 205 / 100 \mathrm{~g}$} & ppm \\
\hline 1 & $\begin{array}{l}\text { Tanah Bekas } \\
\text { Pisang }\end{array}$ & 6.02 & 5.05 & 47.44 & 18.74 & 33.82 & 0.21 & 0.75 & 30.69 & 10.65 \\
\hline 2 & $\begin{array}{l}\text { Tanah Bekas } \\
\text { Padi }\end{array}$ & 5.95 & 6.57 & 21.09 & 42.48 & 36.43 & 0.32 & 1.09 & 65.79 & 16.54 \\
\hline
\end{tabular}

\section{Jumlah anakan}

Anakan pada rumpun pisang kepok yang diteliti pada lokasi Samberah desa Batu-batu kecamatan Muara Badak kutai Kartanegara dapat dilihat pada tabel 8. Jumlah anakan pada rumpun pisang kepok kuning pada lahan bekas tanaman padi dan bekas tanaman pisang yaitu 7,3 pohon; 9,8 pohon dengan rata-rata 8,55 pohon anakan dalam satu rumpun Suatu populasi anakan pisang yang cukup banyak melebihi rekomendasi sebanyak 3 sampai 4 pohon anakan perumpun (Kantor Deputi Menegristek 2000)(6) 
Tabel 7 Jumlah anakan tanaman pisang kepok kuning pada lahan bekas tanaman padi dan lahan bekas tanaman pisang Samberah desa Batu-batu kecamatan Muara Badak Kutai Kartanegara (pohon)

\begin{tabular}{|c|c|c|c|c|c|c|c|c|c|c|c|c|}
\hline Jumlah Anakan & 1 & 2 & 3 & 4 & 5 & 6 & 7 & 8 & 9 & 10 & Total & Rata Rata \\
\hline L padi & 4 & 7 & 8 & 7 & 12 & 5 & 9 & 8 & 5 & 8 & 73 & 7,3 \\
\hline L. pisang & 16 & 12 & 10 & 11 & 7 & 10 & 5 & 9 & 9 & 9 & 98 & 9,8 \\
\hline Total & 20 & 19 & 18 & 18 & 19 & 15 & 14 & 17 & 14 & 17 & 171 & \\
\hline
\end{tabular}

\section{Produksi}

Poduksi pisang kepok yang diteliti pada lokasi Samberah desa Batu-batu kecamatan Muara Badak kutai Kartanegara dapat dilihat pada tabel 9. Produksi pisang kepok kuning tidak berbeda nyata yaitu pada lahan bekas tanaman padi menghasilkan hanya 1 pohon berbuah dengan jumlah 5 sisir, sedangkan dilahan bekas tanaman pisang terdapat 4 pohon yang berbuah dengan jumlah sisir rata-rata 4,25 sisir. Penurunan produksi dari jumlah sisir pisang $10-16$ sisir seperti dilaporkan oleh Widyastuti dan Paimin pada tahun 1993 (8). Hafid 2017 (2) melaporkan produksi pisang kepok kuning pada lokasi Samberah dengan rata-rata produksi 8 sisir demikian juga halnya dengan data produksi pada lokasi yang sama oleh Noor dan Arsensi 2017 (9).

\section{Kesimpulan}

Kesimpulan dari penelitian terhadap pisang kepok kuning pada lahan bekas tanaman padi dan pisang menghasilkan :

1. Budidaya pisang kepok kuning tidak memilih lokasi penanaman

2. Lahan budidaya pisang kepok kuning dapat ditanami berulang-ulang.

3. Jumlah anakan pada rumpun sebaiknya dibatasi maksimal empat pohon.

\section{UCAPAN TERIMA KASIH}

Suksesnya penelitian ini sangat didukung oleh berbagai pihak, untuk ini kami ucapkan terima kasih kepada :

1. Rektor UWGM Samarinda Dr. Drs Ali Mushopa MM., yang mengalokasikan dana penelitian sehingga dapat berjalan tanpa hambatan yang berarti.

2. Dekan Dr. Ahmad Sopian SP.MP. dan Ketua Prodi Agroteknologi Fakultas Pertanian UWGM Zainudin, SP., MSc yang memberikan ijin persetujuan proposal dan laporan penelitian
3. Ketua LPPM yang memberikan penugasan untuk melaksanakan penelitian pada tahun anggaran 2019/2020 pada DIPA UWGM Samarinda

4. Mahasiswa Ramadansyah yang membantu dalam proses pengambilan data lapangan.

5. Semua pihah yang membantu terselenggaranya dan suksesnya penelitian pisang kepok kuning ini. Semoga segala kebaikan yang telah dilakukan menjadi amal saleh dan mendapat barokah dari Allah swt Amin.

\section{Daftar pustaka}

BPS 2017. Statistik Tanaman Buah-Buahan dan Sayuran Tahunan Indonesia 2017. Badan Pusat Statistik Republik Indonesia.Jakarta. $60 \mathrm{~h}$.

Buckman H.O. dan N.C. Brady. 1982 Ilmu Tanah (terjemahan) Bhratara Karya Aksara. Jakarta.

Hafis 2018. Pengaruh pemberian pupuk kompos dan pemangkasan serta pengapuran terhadap pertumbuhan dan produksi pisang kapok kuning. Skripsi. Fakultas Pertanian Uwgm Samarinda

Hardjowigeno,S. 2007. Ilmu Tanah. Akademika Presindo. Jakarta.

Hermina dan Prihatini. Konteks Gizi Seimbang: Analisis Lanjut Survei Konsumsi Makanan Individu (SKMI) 2014//Hermina dan Prihatini S Pusat Penelitian dan Pengembangan Upaya Kesehatan Masyarakat Buletin Penelitian Kesehatan, Vol. 44, No. 3, September 2016 : 205 $-218$

Kantor Deputi Menegristek 2000, Teknoloi tepata guna Budidaya Pisang. Kantor Deputi Menegristek Bidang Pendayagunaan dan Pemasyarakatan Ilmu Pengetahuan dan Teknologi. Jakarta , http://www.ristek.go.id 
Noor, R.B.2017.Analisis Jumlah Anakan Pisang Terhadap Produksi Pisang Kepok Kuning Muara Badak Kutai Kartanegara.Fakultas Pertanian UWGM Samarinda

Noor RB dan Arensi.I. 2018. Pengaruh perlakuan budidaya sehat terhadap pertumbuhan dan produksi pisang kapok kuning didesa Batu-batu Kecamatan Muara Badak. Jurnal Agrotek Faperta Uwgm Samarinda.

Redaksi Trubus, 2008. Berkebun Pisang Secara Intensif, Penebar Swadaya, Jakarta $10 \mathrm{~h}$.

Rizal M. dan Afrilia W. 2015. Prospek pengembangan pisang kepok di Kabupaten Kutai Timur, Kalimantan Timur. Pros sem nas masy biodiv indon.Vol 1, No 8, Desember 2015

Satuhu dan Supriyadi, 2000 Pisang : Budidaya, Pengolahan dan Prospek Pisang Penebar Swadaya Jakarta

Suyanti,. dan S. Ahmad. 2009. Pisang, budi daya, pengolahan, dan prospek pasar. Penebar Swadaya. Depok

Widyastuti, Yustina E, Paimin FB. 1993. Mengenal Buah Unggul Indonesia. Penebar Swadaya, Jakarta. 